\title{
Interleukin-24 inhibits osteosarcoma cell migration and invasion via the JNK/c-Jun signaling pathways
}

\author{
BAOBIAO ZHUO ${ }^{1}$, YINGCHUN SHI ${ }^{1}$, HAIHUI QIN ${ }^{1}$, QINGZENG SUN $^{1}$, ZHENGWEI LI $^{1}$, \\ FENGFEI ZHANG ${ }^{1}$, RONG WANG $^{2}$ and XIAODONG WANG ${ }^{3}$ \\ ${ }^{1}$ Department of Surgery, Xuzhou Children's Hospital, Xuzhou, Jiangsu 221006; ${ }^{2}$ Department of Ultrasound, \\ The Affiliated Hospital Xuzhou Medical College, Xuzhou, Jiangsu 221002; ${ }^{3}$ Department of Surgery, \\ The Affiliated Children's Hospital of Soochow University, Suzhou, Jiangsu 221006, P.R. China
}

Received April 16, 2015; Accepted July 20, 2016

DOI: $10.3892 / 01.2017 .5990$

\begin{abstract}
Approximately $25 \%$ of osteosarcoma patients present with clinically detectable metastatic disease at the time of initial diagnosis. High-dose chemotherapy and/or surgery for the treatment of primary metastatic osteosarcoma is ineffective, and $<20 \%$ of patients will survive 5 years from diagnosis. Therefore, the treatment of metastases is critical for the improvement of the prognosis of primary metastatic osteosarcoma patients. We have previously observed that overexpression of interleukin-24 (IL-24) inhibits neuroblastoma cell proliferation, migration and invasion in vitro. The present study investigated whether IL-24 may be a novel agent for osteosarcoma metastasis-suppressive treatment. It was observed that IL-24 is able to inhibit migration and invasion in spontaneously metastasizing human 143B osteosarcoma cells via the c-Jun $\mathrm{N}$-terminal kinase (JNK)/c-Jun signaling pathway. IL-24 was effective in inhibiting JNK and c-Jun phosphorylation to downregulate matrix metalloproteinase (MMP)-2 and MMP-9, which contributed to the suppression of cell migration and invasion. It was concluded that IL-24 may be a potent agent in the inhibition of highly metastatic 143B osteosarcoma cells, and IL-24 may have translational potential as an effective therapeutic agent for the treatment of metastatic osteosarcoma.
\end{abstract}

Correspondence to: Dr Baobiao Zhuo, Department of Surgery, Xuzhou Children's Hospital, 18 Suti North Road, Xuzhou, Jiangsu 221006, P.R. China

E-mail: zhuobaobiao@163.com

Professor Xiaodong Wang, Department of Surgery, The Affiliated Children's Hospital of Soochow University, 303 Jingde Road, Suzhou, Jiangsu 221006, P.R. China

E-mail: wangxiaodongw2014@yeah.net

Key words: interleukin-24, osteosarcoma, migration, invasion, metastasis

\section{Introduction}

Osteosarcoma is a malignant and potentially metastatic primary bone tumor, and occurs most often in children and young adults, typically after age 10 years (1-3). In $20 \%$ of patients with osteosarcoma, clinically detectable metastatic disease is present at the time of diagnosis, and up to $40 \%$ of patients present with advanced metastases (4-6). Despite great advances in multimodal treatment during the previous few decades, patients with metastatic osteosarcoma have a poor prognosis, with 5 -year survival rates of $<20 \%(7,8)$. Thus, it is highly desirable to seek a novel strategy for the treatment of metastatic osteosarcoma.

Interleukin-24 (IL-24), also known as melanoma differentiation-associated 7 due to its initial discovery from human melanoma cells by combined treatment with interferon- $\beta$ and mezerein, is a unique member of the IL-10 family that exhibits almost ubiquitous cancer-specific toxicity, with no harmful effects on normal cells or tissues (9-12). The overproduction of IL-24 may selectively inhibit cancer cell growth and induce apoptosis in a broad spectrum of human cancer types, and additionally induces indirect antitumor activity through inhibition of angiogenesis, activation of the antitumor immune response and sensitization of cancer cells to radiation, chemotherapy and antibody-induced killing (12-14).

Previous studies have mainly focused on the role of IL-24 tumor-suppressive effects by prevention of proliferation and promotion of apoptosis in a wide variety of tumors $(11,14)$. However, it has been observed that IL-24 inhibits neuroblastoma cell migration and invasion by regulating numerous invasion-associated molecules in vitro $(15,16)$. These observations are consistent with the results of other studies, which reported that IL-24 inhibited migration and invasion of human ovarian, liver and lung cancer cells in vitro (17-19). Fisher et al (20) have demonstrated that IL-24 is safe and promotes significant clinical activity, particularly in the context of patients with metastatic melanoma (20). In the present study, we investigated the effects of IL-24 on migration and invasion in spontaneously metastasizing human osteosarcoma 143B cells in vitro, and attempted to identify the associated molecular mechanisms of metastasis suppression. It was demonstrated that IL-24 is able to inhibit migration and 
invasion in spontaneously metastasizing human 143B osteosarcoma cells via inhibiting c-Jun N-terminal kinase (JNK) and c-Jun phosphorylation to downregulate matrix metalloproteinase (MMP)-2 and MMP-9.

\section{Materials and methods}

Virus production, cell line and antibodies. Adenovirus (Ad).IL-24 (a replication-deficient adenovirus with IL-24 gene) and Ad.green fluorescent protein (GFP) (a replication-deficient adenovirus with reporter gene GFP) were maintained in our laboratory as previously described (16). The human highly metastatic osteosarcoma cell line 143B was purchased from the American Type Culture Collection (Manassas, VA, USA) and maintained in Dulbecco's modified Eagle's medium (DMEM) and Ham's F12 (1:1 mixture; Gibco; Thermo Fisher Scientific, Inc., Waltham, MA, USA) supplemented with $10 \%$ fetal bovine serum (Gibco; Thermo Fisher Scientific, Inc.) in a humidified $37^{\circ} \mathrm{C}$ incubator with $5 \% \mathrm{CO}_{2}$. Anti-JNK rabbit antibody (dilution, 1:500; catalog no., sc-572), anti-phosphorylated (p)-JNK rabbit antibody (dilution, 1:400; catalog no., sc-12882) and anti- $\beta$-actin rabbit antibody (dilution, 1:400; catalog no., sc-7210) were purchased from Santa Cruz Biotechnology, Inc. (Dallas, TX, USA). Anti-extracellular signal-regulated kinase (Erk)1/2 rabbit antibody (dilution, 1:1,000; catalog no., \#4695), anti-p-Erk rabbit antibody (dilution, 1:1,000; catalog no., \#4376), anti-p38 rabbit antibody (dilution, 1:1,000; catalog no., \#8690), anti-p-p38 rabbit antibody (dilution, 1:1,000; catalog no., \#4511), anti-c-Jun rabbit antibody (dilution, 1:500; catalog no., \#9165), anti-p-c-Jun rabbit antibody (dilution, 1:500; catalog no., \#2361), anti-MMP-2 rabbit antibody (dilution, 1:1,000; catalog no., \#13132) and anti-MMP-9 rabbit antibody (dilution, 1:1,000; catalog no., \#13667) were purchased from Cell Signaling Technology, Inc. (Danvers, MA, USA).

Cell viability assay. Cell viability was detected by 3-(4,5-dimethylthiazol-2-yl)-2,5-diphenyltetrazolium bromide (MTT) assay as described previously (16). Briefly, the cells were plated in 96 -well plates $\left(1 \times 10^{4}\right.$ cells per well) and infected with Ad.IL-24 or Ad.GFP at the indicated time point (24, 48, 72 or $96 \mathrm{~h}$ ) or multiplicity of infection (MOI; 1, 5, 10, 50 or 100), the medium was removed and fresh medium containing MTT $(0.5 \mathrm{mg} / \mathrm{ml})$ was added to each well. The cells were incubated at $37^{\circ} \mathrm{C}$ for $4 \mathrm{~h}$, and an equal volume of solubilization solution $(0.01 \mathrm{~N} \mathrm{HCl}$ in $10 \%$ sodium dodecyl sulfate) was added to each well and mixed thoroughly. The absorbance at $490 \mathrm{~nm}$ was measured using an ELx-800 spectrometer reader (Bio-Tek Instruments, Inc., Winooski, VT USA). All MTT assays were prepared in triplicate and repeated three times.

Cell migration and invasion assay. 143B cells were seeded at a density of $5 \times 10^{5}$ cells/well in 6 -well tissue culture plates. The following day, cells were infected with Ad.IL-24 and Ad.GFP (control) at $\mathrm{MOI}=10$. At $8 \mathrm{~h}$ subsequent to infection, the cells were trypsinized, washed in phosphate-buffered saline (PBS) and resuspended in serum-free DMEM. The cell migration or invasion assay was performed in a 24-well Transwell unit (Sigma-Aldrich; EMD Millipore, Billerica, MA, USA) or a 24-well Transwell unit coated with Matrigel (BD Biosciences, Franklin Lakes, NJ, USA), respectively. The lower chambers of the Transwell units were filled with serum-free medium, and the upper chambers were seeded with $1 \times 10^{5}$ cells from each group in triplicate wells. Following 24- and 48-h incubations, the cells that had passed through the filter into the lower wells were counted. The experiments were performed four times, and the results were recorded as the mean of these experiments.

Western blotting. Cells were harvested and incubated in lysis buffer containing $20 \mathrm{mmol} / 1$ Tris- $\mathrm{HCl}(\mathrm{pH} \mathrm{7.5),} \mathrm{1 \%} \mathrm{Triton}$ $\mathrm{X}-100,150 \mathrm{mmol} / 1 \mathrm{NaCl}, 10 \%$ glycerol, $1 \mathrm{mmol} / 1 \mathrm{Na}_{3} \mathrm{VO}_{4}$, $50 \mathrm{mmol} / \mathrm{l} \mathrm{NaF}, 100 \mathrm{mmol} / \mathrm{l}$ phenylmethylsulfonyl fluoride and a commercial protease inhibitor mixture (Roche Diagnostics, Basel, Switzerland) for 20 min on ice. After insoluble debris was pelleted by centrifugation at $14,000 \times \mathrm{g}$ for $15 \mathrm{~min}$ at $4^{\circ} \mathrm{C}$, the supernatants were collected and determined for protein content using the Bradford method (Bio-Rad Laboratories, Inc., Hercules, CA, USA). Proteins (50 $\mu \mathrm{g}$ ) were resolved under denaturing conditions by $12 \%$ sodium dodecyl sulfate-polyacrylamide gel electrophoresis and transferred onto nitrocellulose membranes. Following blocking for $2 \mathrm{~h}$ in PBS with $0.1 \%$ Tween 20 and 3\% bovine serum albumin (Beyotime Institute of Biotechnology, Haimen China), the membranes were incubated overnight at $4^{\circ} \mathrm{C}$ with the appropriate primary antibodies. Membranes were then washed with PBS and incubated with alkaline phosphatase-conjugated goat anti-rabbit secondary antibody (dilution, 1:10,000; catalog no., A3687; Sigma-Aldrich; EMD Millipore) for $2 \mathrm{~h}$. Membranes were developed using the nitro-blue tetrazolium chloride/5-bromo-4-chloro-3'-indolyphosphate p-toluidine salt color substrate (Promega Corporation, Madison, WI, USA). The density of the bands on the membrane was scanned and analyzed using an image analyzer. The bands on the membranes were visualized and quantified with an Odyssey ${ }^{\circledR}$ CLx Infrared Imaging System (LI-COR Biosciences, Lincoln, NE, USA).

Use of SP600125 in cell culture. SP600125 (Sigma-Aldrich; EMD Millipore) was dissolved in dimethyl sulfoxide (Sigma-Aldrich; EMD Millipore), as a $20 \mathrm{mM}$ stock solution, and further diluted $(1: 1,000)$ in culture medium to administer to treatment group cells. Following treatment with $20 \mu \mathrm{M}$ SP600125, 143B cells were infected with Ad.IL-24 or Ad.GFP at $\mathrm{MOI}=10$ for $48 \mathrm{~h}$.

Statistical analysis. Data are expressed as the mean \pm standard deviation. Statistical analysis of the results was performed using a one-way analysis of variance or Student's t-test. The experimental data were analyzed using SPSS version 16.0 (SPSS, Inc., Chicago, IL, USA). P<0.05 was considered to indicate a statistically significant difference.

\section{Results}

IL-24 inhibits osteosarcoma $143 B$ cell proliferation. In the present study, the expression of IL-24 in 143B cells was investigated via adenoviral infection. As shown in Fig. 1A and B, IL-24 protein levels were efficiently augmented following infection with Ad.IL-24 for $48 \mathrm{~h}$ compared to Ad.GFP as assayed by western blotting. Subsequently, the effects on 143B cells proliferative ability were assessed by MTT assay following infection with Ad.IL-24 or Ad.GFP at various MOI 
A
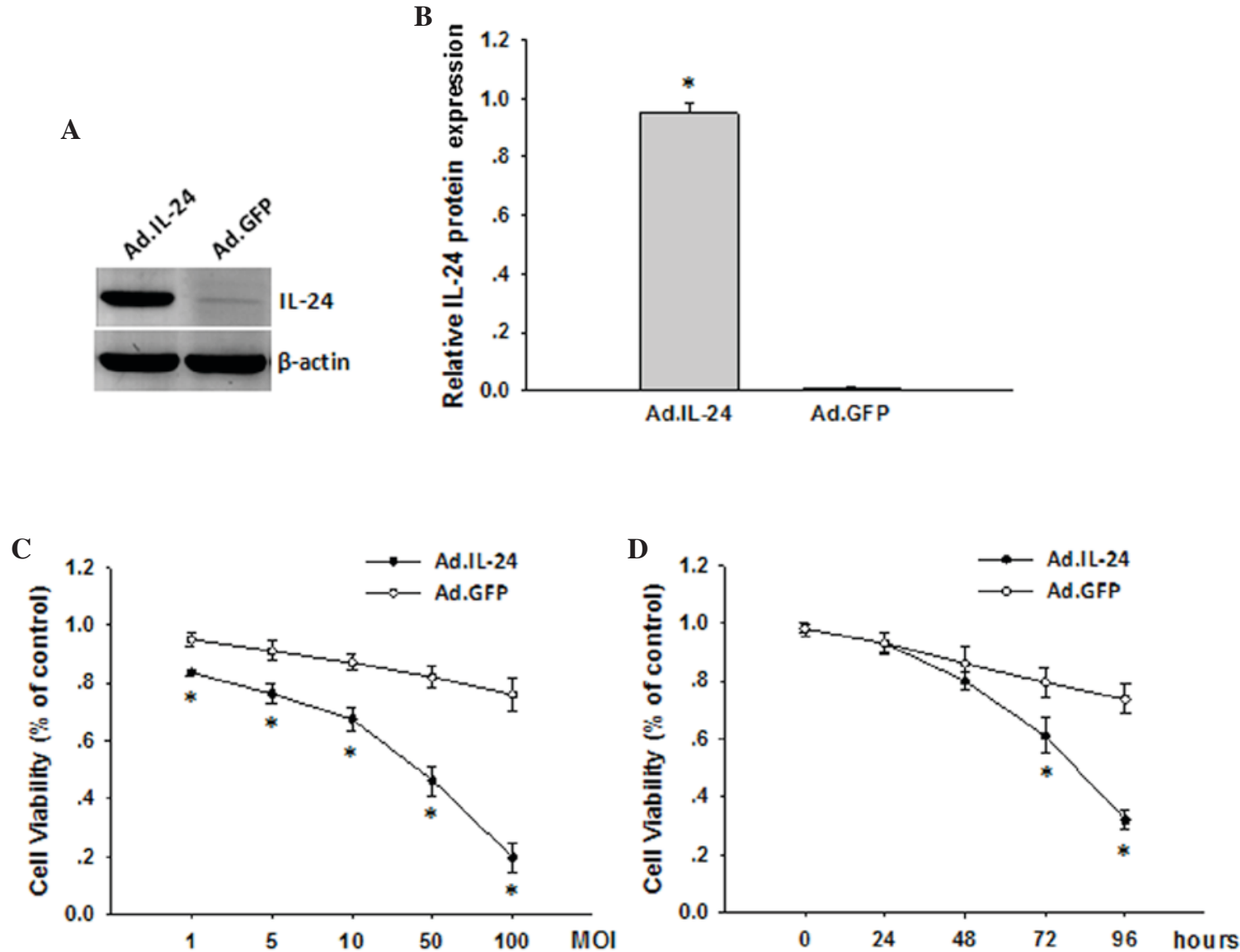

Figure 1. Overexpression of IL-24 suppresses osteosarcoma 143B cell proliferation. (A) Overexpression of IL-24 in 143B cells was analyzed by western blotting. $\beta$-actin was used as an internal control. (B) Quantitative representation of the expression of IL-24 protein. Data are presented as the mean \pm SD from three independent experiments $(\mathrm{n}=3)$. (C) 143B cells were seeded into 96-well plates and treated with Ad.IL-24 and Ad.GFP, respectively, at MOI=1, 5, 10, 50 and 100. Following $72 \mathrm{~h}$ of infection, the cell viability was measured by MTT assays. (D) 143B cells were seeded into 96-well plates and treated with Ad.IL-24 and Ad.GFP, respectively, at MOI=10. The cell viability was measured by MTT assays at $24,48,72$ and $96 \mathrm{~h}$ following treatment. Following infection for $48 \mathrm{~h}$, no significant inhibition of tumor cell proliferation was observed in Ad.IL-24 treated cells compared to Ad.GFP treated cells. Data are presented as the mean \pm SD from three independent experiments $(\mathrm{n}=3)$. ${ }^{*} \mathrm{P}<0.05$ compared with Ad.GFP. IL, interleukin; Ad, adenovirus; GFP, green fluorescent protein; MOI, multiplicity of infection; MTT, 3-(4,5-dimethylthiazol-2-yl)-2,5-diphenyltetrazolium bromide; SD, standard deviation.
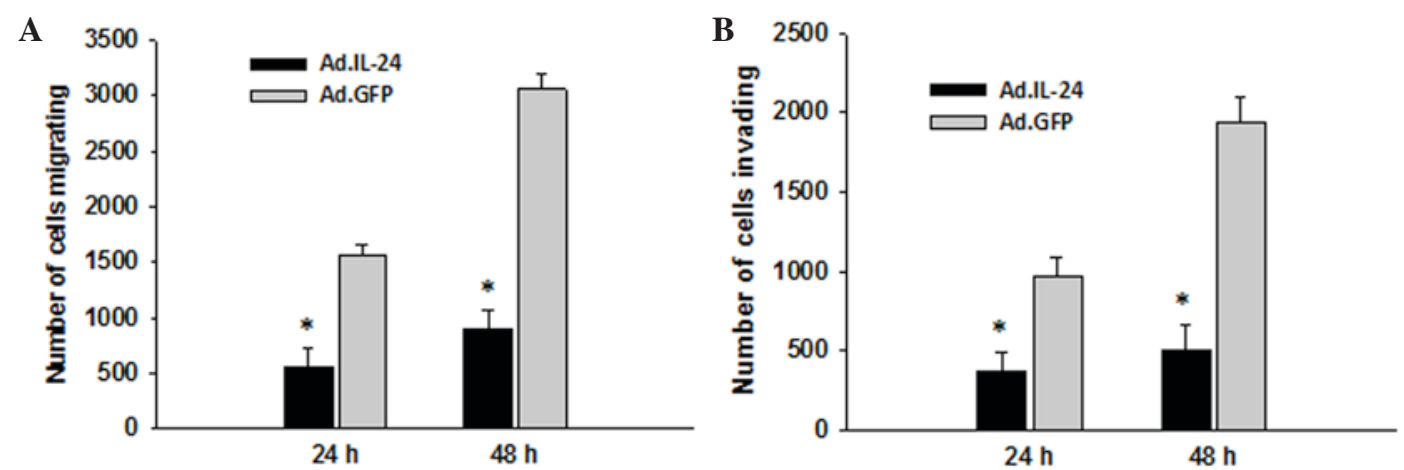

Figure 2. Overexpression of IL-24 inhibits tumor cell migration and invasion. 143B cells were treated with Ad.IL-24 and Ad-GFP in order to investigate cell migration and invasion at 24 and $48 \mathrm{~h}$ subsequent to treatment. (A) Cells treated with Ad.IL-24 were significantly less able to migrate compared with cells treated with Ad.GFP. (B) Cells treated with Ad.IL-24 demonstrated less invasion compared with cells treated with Ad.GFP. Data are presented as the mean \pm standard deviation from four independent experiments $(n=4)$. " $\mathrm{P}<0.05$ compared with Ad.GFP. IL, interleukin; Ad, adenovirus; GFP, green fluorescent protein.

or at various time points. As shown in Fig. 1C, overexpression of IL-24 markedly inhibited the growth of the infected 143B cells in a dose-dependent manner. Simultaneously, the proliferation of 143B cells was significantly inhibited at $72 \mathrm{~h}$ following infection with Ad.IL-24 (Fig. 1D; P=0.0036). This indicated that IL-24 was able to effectively inhibit the proliferation of 143B cells.

IL-24 inhibits osteosarcoma $143 B$ cell migration and invasion. Subsequently, the present study detected the effects 

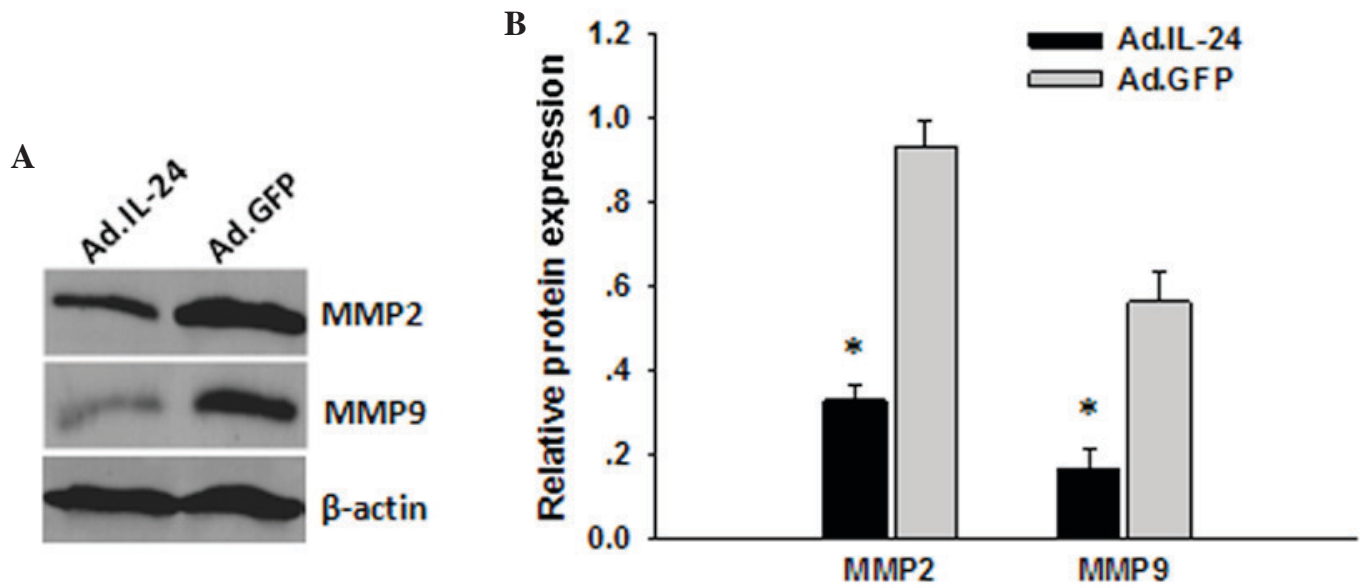

Figure 3. IL-24 inhibits MMP-2 and MMP-9 expression. 143B cells were treated with Ad.IL-24 or Ad.GFP. At $48 \mathrm{~h}$ subsequent to treatment, cell lysate was collected and analyzed for MMP-2 and MMP-9 protein by western blotting. (A) Inhibition of MMP-2 and MMP-9 expression was observed in 143B cells treated with Ad.IL-24. (B) Quantitative representation of the expression of MMP-2 and MMP-9 proteins. Data are presented as the mean \pm standard deviation from three independent experiments $(\mathrm{n}=3)$. "P<0.05 compared with Ad.GfP. IL, interleukin; MMP, matrix metalloproteinase; Ad, adenovirus; GFP, green fluorescent protein.

A

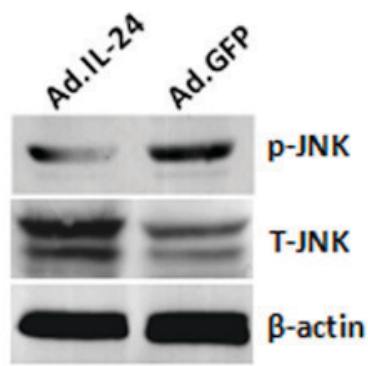

C

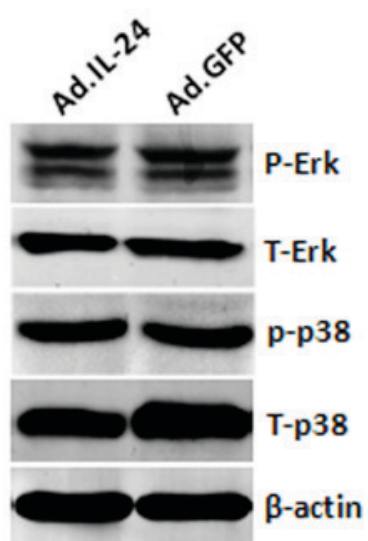

B

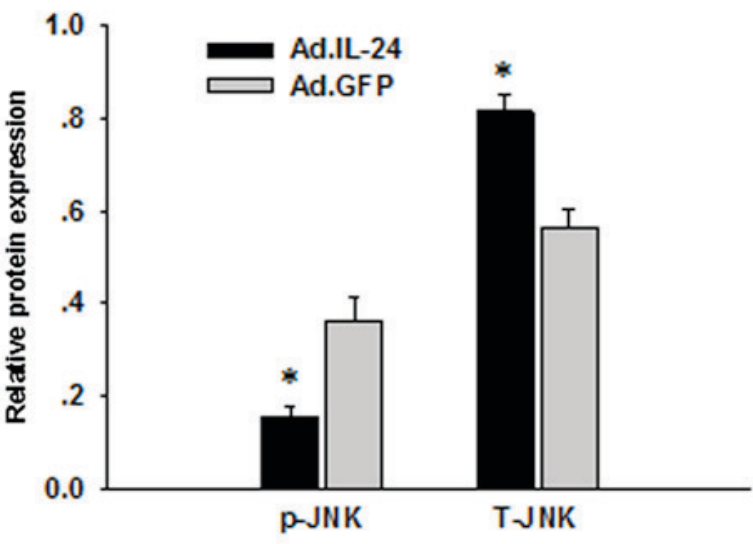

D

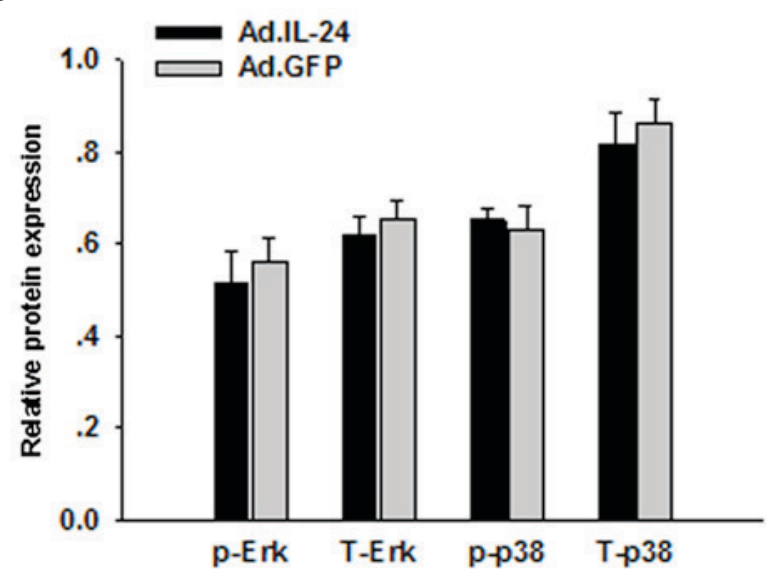

Figure 4. IL-24 inhibits 143B cell invasion and is associated with the JNK signaling pathway. Osteosarcoma 143B cells were treated with Ad.IL-24 or Ad.GFP. (A and B) Cells were harvested at $48 \mathrm{~h}$, total cell lysates were prepared and the expression of the indicated proteins was analyzed by western blotting. $\beta$-actin was used as a loading control. (C and D) Quantitative representation of the expression of proteins. Data are presented as the mean \pm standard deviation from three independent experiments ( $\mathrm{n}=3$ ). " $\mathrm{P}<0.05$ compared with Ad.GFP. IL, interleukin; JNK, c-Jun N-terminal kinase; Ad, adenovirus; GFP, green fluorescent protein; p, phosphorylated; Erk, extracellular signal-regulated kinase; T, total.

on $143 \mathrm{~B}$ cells migration and invasion ability following infection with Ad.IL-24 or Ad.GFP at MOI=10 for $48 \mathrm{~h}$ by using Transwell assays. It was observed that overexpression of IL-24 was able to significantly decrease $143 \mathrm{~B}$ cell migration ability (Fig. 2A; $\mathrm{P}=0.0006$ ), and this effect was consistent across the invasion assay (Fig. 2B; $\mathrm{P}=0.0003$ ). 143B cell viability was 


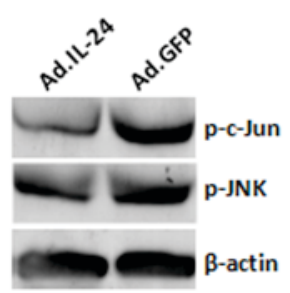

D

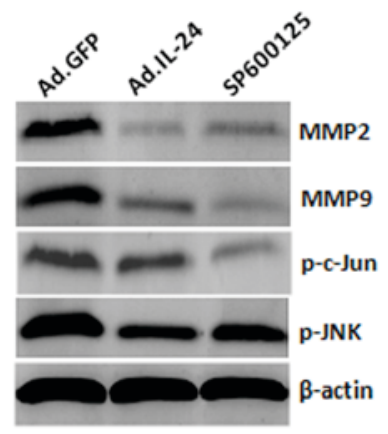

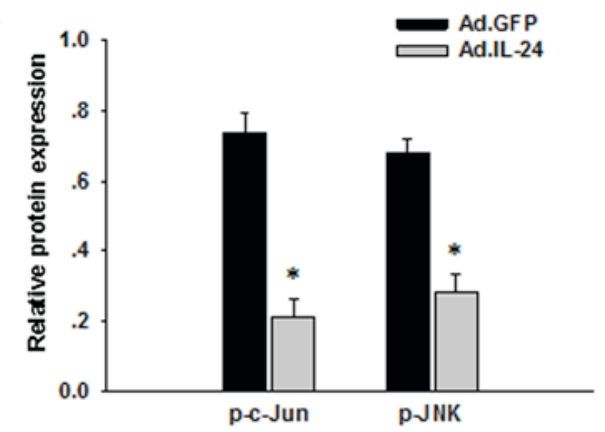

$\mathbf{E}$
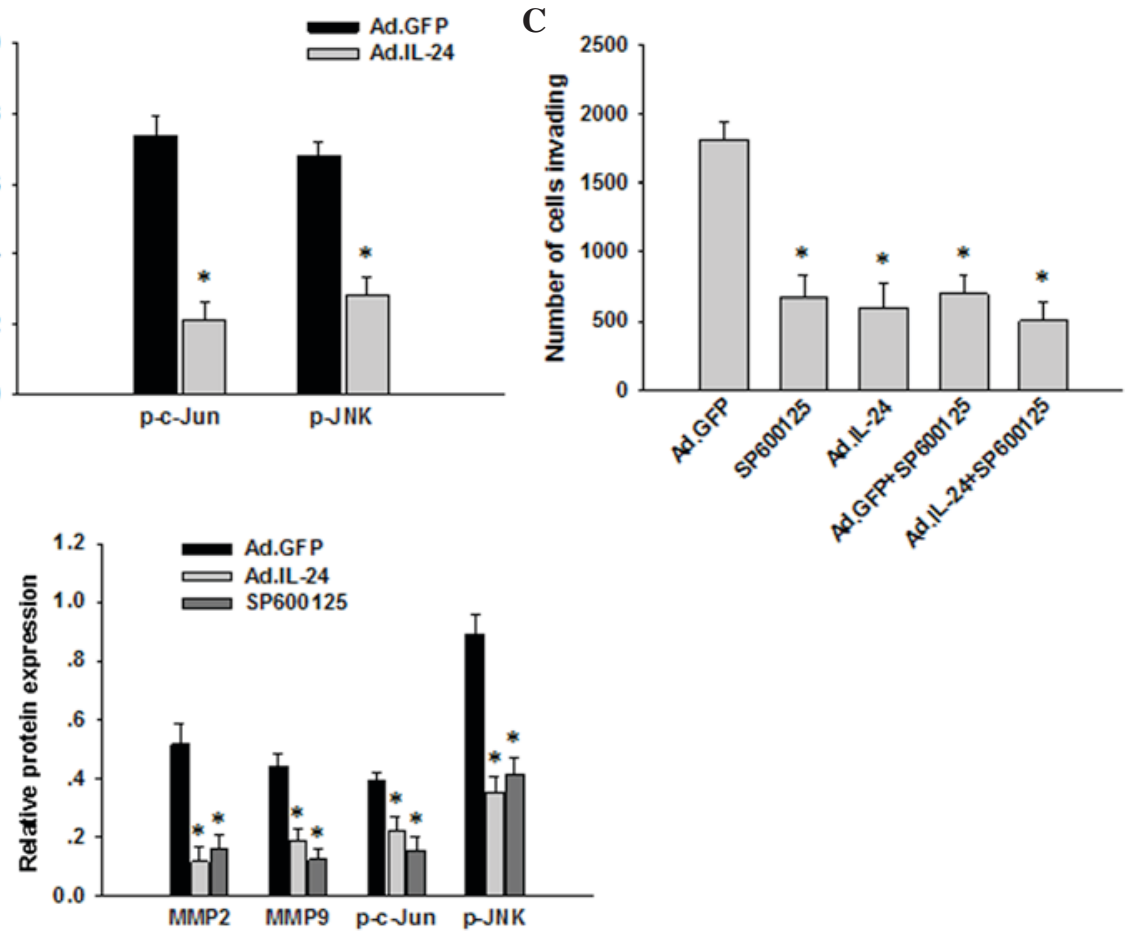

Figure 5. IL-24 inhibits osteosarcoma cell invasion through the JNK/c-Jun signaling pathway. (A) The expression of p-c-Jun and p-JNK was analyzed by western blotting using 143B cells that were treated with Ad.IL-24 or Ad.GFP. (B) Quantitative representation of the expression of proteins. Data are presented as the mean \pm SD from three independent experiments $(n=3)$. (C) The JNK signaling pathways were blocked with the specific inhibitor SP600125 in the 143B cells, followed by infection with Ad.IL-24 or Ad.GFP for $48 \mathrm{~h}$. Cell invasion was detected using a Matrigel invasion assay. Data are presented as the mean \pm SD from four independent experiments $(n=4)$. (D) Expression of the indicated proteins was analyzed by western blotting. $\beta$-actin was used as a loading control. (E) Quantitative representation of the expression of proteins. Data are presented at the mean $\pm \mathrm{SD}$ from three independent experiments $\left(\mathrm{n}=3\right.$ ). ${ }^{*} \mathrm{P}<0.05$ compared with Ad.GFP. IL, interleukin; JNK, c-Jun N-terminal kinase; p, phosphorylated; Ad, adenovirus; GFP, green fluorescent protein; SD, standard deviation; MMP, matrix metalloproteinase.

investigated at $48 \mathrm{~h}$ following infection with Ad.IL-24 and the results are presented in Fig. 1D. Treatment with Ad.IL-24 at $48 \mathrm{~h}$ did not significantly inhibit the proliferation of 143B cells $(\mathrm{P}=0.7426)$. This indicated that IL-24 inhibits $143 \mathrm{~B}$ cell migration and invasion independently of IL-24 cytotoxicity.

IL-24 reduces $M M P-2$ and MMP-9 expression. To determine the underlying molecular mechanism of IL-24 inhibition of migration and invasion, the level of migration- and invasion-associated proteins in 143B cells was detected following treatment with Ad.IL-24. MMP-2 and MMP-9 have a critical role in osteosarcoma cell migration and invasion (21). To investigate whether MMP-2 and MMP-9 are involved in IL-24 inhibition of the migration and invasion of osteosarcoma cells, the present study assessed the levels of MMP-2 and MMP-9 in osteosarcoma cells treated with Ad.IL-24 at MOI=10 for $48 \mathrm{~h}$ by western blotting. Results presented in Fig. 3A and B indicated that the levels of MMP-2 and MMP-9 were reduced in the Ad.IL-24 group compared with the control group. This reduction may have led to the inhibition of migration and invasion in 143B cells following treatment with Ad.IL-24.

JNK/c-Jun signaling pathway is associated with IL-24-induced cell migration and invasion. The mitogen-associated protein kinase (MAPK) signaling pathway is closely associated with osteosarcoma cell migration and invasion. Therefore, to determine whether IL-24 regulates 143B cell migration and invasion via the MAPK signaling pathway, the present study investigated the signaling pathways that were activated by IL-24. 143B cells were pre-treated with Ad.IL-24 at $\mathrm{MOI}=10$ for $48 \mathrm{~h}$ and compared with the Ad.GFP treatment group. Following treatment, total protein was extracted and analyzed by western blotting. As shown in Fig. 4, p-JNK was significantly decreased in the 143B cells following Ad.IL-24 treatment $(\mathrm{P}<0.0001)$. However, there were no marked changes in the levels of $\mathrm{p}$-Erk $(\mathrm{P}=0.0689)$ or $\mathrm{p}-\mathrm{p} 38(\mathrm{P}=0.0732)$ caused by IL-24 overexpression (Fig. 4).

Subsequently, the present study additionally determined the association between the migration function of IL-24 and the JNK signaling pathway. Western blotting revealed that when $\mathrm{p}-\mathrm{JNK}$ levels were decreased by IL-24 overexpression in the 143B cells, p-c-Jun levels were also decreased (Fig. 5A and B). These results suggest that IL-24 may regulate p-c-Jun through p-JNK in osteosarcoma cells. To further determine whether IL-24 regulates $143 \mathrm{~B}$ cell invasion through the JNK/c-Jun signaling pathways, the JNK pathways were blocked with the specific inhibitor SP600125 in the 143B cells and subsequently infected with Ad.IL-24 or Ad.GFP at MOI=10 for $48 \mathrm{~h}$. As shown in Fig. 5C, 143B cells pre-treated with SP600125 and infected with Ad.IL-24 did not demonstrate a marked difference in inhibition of invasion compared with cells treated with SP600125 or Ad.IL-24 alone. Furthermore, when p-JNK levels were decreased by SP600125 treatment in the 143B cells, p-c-Jun, MMP-2 and MMP-9 levels were also decreased (Fig. 5D and E). These results suggest that the JNK/c-Jun signaling pathways may 
have important roles in mediating IL-24 inhibited osteosarcoma cell migration and invasion.

\section{Discussion}

Enforced expression of IL-24 inhibits the growth of a broad spectrum of cancer cells, without exerting deleterious effects in normal cells and tissues. Previously, our and others' data have demonstrated that overexpressed IL-24 may inhibit migration and invasion in human ovarian, liver and lung cancer cells and neuroblastoma in vitro (15,17-19). In the present study, anti-proliferative effects were observed following overexpression of IL-24 in osteosarcoma cells. Anti-invasion and anti-migration effects of IL-24 overexpression were also observed on highly metastatic 143B osteosarcoma cells. Treatment with Ad.IL-24 at $48 \mathrm{~h}$ did not significantly inhibit the proliferation of 143B cells. However, treatment with Ad.IL-24 at 48 h significantly decreased $143 \mathrm{~B}$ cell migration and invasion. Therefore, the results of the present study appear to indicate that the suppressive role of IL-24 on osteosarcoma cell migration and invasion is independent of IL-24 cytotoxicity. Thus, the present study further clarified the associative mechanism by which IL-24 regulates migration and invasion of human osteosarcoma cells.

To facilitate tumor cell migration and invasion, cells must alter their cell-cell properties, rearrange the extracellular matrix (ECM) environment and reorganize their cytoskeletons (22-25). ECM degradation is vital for migration of the metastatic cell from the primary tumor site and invasion to the metastatic site (26). MMPs are a zinc-dependent endopeptidase family known to be responsible for the degradation of the ECM $(27,28)$. Among the MMP family members, MMP-2 and MMP-9 have significant roles in tumor metastasis by degrading collagen and stimulating tumor growth (27). The suppression of MMP-2 and MMP-9 may be effective approaches for anti-metastasis treatment of cancer. The results of the present study indicated that the expression levels of MMP-2 and MMP-9 were suppressed by IL-24. Thus, one potential mechanism that may explain IL-24 as a migration and invasion suppressor is negative regulation of the MMP signaling pathways.

MAPK signaling pathways are associated with tumorigenesis and metastatic potential in osteosarcoma $(29,30)$. In addition, MAPKs have a role in major signaling pathways that control MMPs (25). A number of studies have demonstrated that stress-activated protein kinases/JNK and Erk transcriptionally regulate the expression of MMP-2 and MMP-9, which results in regulation of cell migration and invasion (31-34). Silibinin is able to suppress osteosarcoma MG-63 cell invasion by inhibiting c-Jun/activator protein 1 induction of MMP-2 (35). Statin reduces osteosarcoma cell migration and invasion though JNK-c-Jun-MMP-2 signaling pathways to inhibit 3-hydroxy-3-methylglutaryl-coenzyme A reductase (36). In the present study, IL-24 was overexpressed in osteosarcoma 143B cells, and it was observed that the activation of JNK/c-Jun was inhibited, which may be responsible for the downregulation of MMP-2 and MMP-9.

In summary, to the best of our knowledge, the present study is the first to provide evidence that IL-24 is able to inhibit osteosarcoma invasion through the JNK/c-Jun signaling pathway, via decreasing MMP-2/MMP-9 levels. Understanding the molecular mechanism by which IL-24 inhibits osteosarcoma progression will not only improve our understanding of the metastatic mechanisms of osteosarcoma but may also provide a novel potential therapeutic agent for the treatment of metastatic osteosarcoma.

\section{References}

1. Ritter J and Bielack SS: Osteosarcoma. Ann Oncol 21 (Suppl 7): vii320-vii325, 2010

2. Terezhalmy GT, Riley CK and Moore WS: Osteosarcoma. Quintessence Int 31: 592-593, 2000.

3. Moore DD and Luu HH: Osteosarcoma. Cancer Treat Res 162: 65-92, 2014.

4. Meyers PA, Heller G, Healey JH, Huvos A, Applewhite A, Sun M and LaQuaglia M: Osteogenic sarcoma with clinically detectable metastasis at initial presentation. J Clin Oncol 11: 449-453, 1993

5. Kager L, Zoubek A, Pötschger U, Kastner U, Flege S, Kempf-Bielack B, Branscheid D, Kotz R, Salzer-Kuntschik M, Winkelmann W, et al; Cooperative German-Austrian-Swiss Osteosarcoma Study Group: Primary metastatic osteosarcoma: Presentation and outcome of patients treated on neoadjuvant Cooperative Osteosarcoma Study Group protocols. J Clin Oncol 21: 2011-2018, 2003.

6. Rasalkar DD, Chu WC, Lee V, Paunipagar BK, Cheng FW and Li CK: Pulmonary metastases in children with osteosarcoma: Characteristics and impact on patient survival. Pediatr Radiol 41: 227-236, 2011.

7. Meyers PA, Schwartz CL, Krailo M, Kleinerman ES, Betcher D, Bernstein ML, Conrad E, Ferguson W, Gebhardt M, Goorin AM, et al: Osteosarcoma: A randomized, prospective trial of the addition of ifosfamide and/or muramyl tripeptide to cisplatin, doxorubicin, and high-dose methotrexate. J Clin Oncol 23: 2004-2011, 2005.

8. Meyers PA, Schwartz CL, Krailo MD, Healey JH, Bernstein ML, Betcher D, Ferguson WS, Gebhardt MC, Goorin AM, Harris M, et al; Children's Oncology Group: Osteosarcoma: The addition of muramyl tripeptide to chemotherapy improves overall survival - a report from the Children's Oncology Group. J Clin Oncol 26: 633-638, 2008.

9. Jiang H, Lin JJ, Su ZZ, Goldstein NI and Fisher PB: Subtraction hybridization identifies a novel melanoma differentiation associated gene, mda-7, modulated during human melanoma differentiation, growth and progression. Oncogene 11: 2477-2486, 1995.

10. Caudell EG, Mumm JB, Poindexter N, Ekmekcioglu S, Mhashilkar AM, Yang XH, Retter MW, Hill P, Chada S and Grimm EA: The protein product of the tumor suppressor gene, melanoma differentiation-associated gene 7, exhibits immunostimulatory activity and is designated IL-24. J Immunol 168: 6041-6046, 2002.

11. Sauane M, Gopalkrishnan RV, Sarkar D, Su ZZ, Lebedeva IV, Dent P, Pestka S and Fisher PB: MDA-7/IL-24: Novel cancer growth suppressing and apoptosis inducing cytokine. Cytokine Growth Factor Rev 14: 35-51, 2003.

12. Whitaker EL, Filippov VA and Duerksen-Hughes PJ: Interleukin 24: Mechanisms and therapeutic potential of an anti-cancer gene. Cy tokine Growth Factor Rev 23: 323-331, 2012.

13. Su ZZ, Lebedeva IV, Sarkar D, Emdad L, Gupta P, Kitada S, Dent P, Reed JC and Fisher PB: Ionizing radiation enhances therapeutic activity of mda-7/IL-24: Overcoming radiation- and mda-7/IL-24-resistance in prostate cancer cells overexpressing the antiapoptotic proteins bcl-xL or bcl-2. Oncogene 25: 2339-2348, 2006.

14. Dent P, Yacoub A, Hamed HA, Park MA, Dash R, Bhutia SK, Sarkar D, Wang XY, Gupta P, Emdad L, et al: The development of MDA-7/IL-24 as a cancer therapeutic. Pharmacol Ther 128: 375-384, 2010.

15. Zhuo B, Wang R, Zhang H, Qin H, Y in Y and Shi Y: Interleukin-24 inhibits cell migration and invasion in the neuroblastoma cell line SH-SY5Y. Oncol Rep 30: 2749-2754, 2013.

16. Zhuo B, Wang R, Yin Y, Zhang H, Ma T, Liu F, Cao H and Shi Y: Adenovirus arming human IL-24 inhibits neuroblastoma cell proliferation in vitro and xenograft tumor growth in vivo. Tumour Biol 34: 2419-2426, 2013. 
17. Ramesh R, Ito I, Gopalan B, Saito Y, Mhashilkar AM and Chada S Ectopic production of MDA-7/IL-24 inhibits invasion and migration of human lung cancer cells. Mol Ther 9: 510-518, 2004.

18. Shi H, Wei LL, Yuan CF, Yang JX, Yi FP, Ma YP and Song FZ: Melanoma differentiation-associated gene-7/interleukin 24 inhibits invasion and migration of human cervical cancer cells in vitro. Saudi Med J 28: 1671-1675, 2007.

19. Xiao CW, Xue XB, Zhang H, Gao W, Yu Y, Chen K, Zheng JW and Wang CJ: Oncolytic adenovirus-mediated MDA-7/IL-24 overexpression enhances antitumor activity in hepatocellular carcinoma cell lines. Hepatobiliary Pancreat Dis Int 9: 615-621, 2010.

20. Fisher PB, Sarkar D, Lebedeva IV, Emdad L, Gupta P, Sauane M, Su ZZ, Grant S, Dent P, Curiel DT, et al: Melanoma differentiation associated gene-7/interleukin-24 (mda-7/IL-24): Novel gene therapeutic for metastatic melanoma. Toxicol Appl Pharmacol 224: 300-307, 2007.

21. Bjørnland K, Flatmark K, Pettersen S, Aaasen AO, Fodstad O and Maelandsmo GM: Matrix metalloproteinases participate in osteosarcoma invasion. J Surg Res 127: 151-156, 2005.

22. Yamaguchi H, Wyckoff J and Condeelis J: Cell migration in tumors. Curr Opin Cell Biol 17: 559-564, 2005.

23. Carragher NO and Frame MC: Focal adhesion and actin dynamics: A place where kinases and proteases meet to promote invasion. Trends Cell Biol 14: 241-249, 2004.

24. Pickup MW, Mouw JK and Weaver VM: The extracellular matrix modulates the hallmarks of cancer. EMBO Rep 15: 1243-1253, 2014.

25. Wolf K, Wu YI, Liu Y, Geiger J, Tam E, Overall C, Stack MS and Friedl P: Multi-step pericellular proteolysis controls the transition from individual to collective cancer cell invasion. Nat Cell Biol 9: 893-904, 2007.

26. Wolf $\mathrm{K}$ and Friedl P: Extracellular matrix determinants of proteolytic and non-proteolytic cell migration. Trends Cell Biol 21: 736-744, 2011.

27. McCawley LJ and Matrisian LM: Matrix metalloproteinases: Multifunctional contributors to tumor progression. Mol Med Today 6: 149-156, 2000.
28. Kessenbrock K, Plaks V and Werb Z: Matrix metalloproteinases: Regulators of the tumor microenvironment. Cell 141: 52-67, 2010.

29. Khanna C, Wan X, Bose S, Cassaday R, Olomu O, Mendoza A, Yeung C, Gorlick R, Hewitt SM and Helman LJ: The membrane-cytoskeleton linker ezrin is necessary for osteosarcoma metastasis. Nat Med 10: 182-186, 2004.

30. Huang CY, Lee CY, Chen MY, Yang WH, Chen YH, Chang CH, Hsu HC, Fong YC and Tang CH: Stromal cell-derived factor-1/CXCR4 enhanced motility of human osteosarcoma cells involves MEK1/2, ERK and NF-kappaB-dependent pathways. J Cell Physiol 221: 204-212, 2009.

31. Iiizumi M, Bandyopadhyay S, Pai SK, Watabe M, Hirota S, Hosobe S, Tsukada T, Miura K, Saito K, Furuta E, et al: RhoC promotes metastasis via activation of the Pyk 2 pathway in prostate cancer. Cancer Res 68: 7613-7620, 2008.

32. Huang Q, Lan F, Wang X, Yu Y, Ouyang X, Zheng F, Han J, Lin Y, Xie Y, Xie F, et al: IL-1 $\beta$-induced activation of p38 promotes metastasis in gastric adenocarcinoma via upregulation of AP-1/c-fos, MMP2 and MMP9. Mol Cancer 13: 18, 2014.

33. Moon SK, Kim HM, Lee YC and Kim CH: Disialoganglioside (GD3) synthase gene expression suppresses vascular smooth muscle cell responses via the inhibition of ERK1/2 phosphorylation, cell cycle progression, and matrix metalloproteinase- 9 expression. J Biol Chem 279: 33063-33070, 2004.

34. Gao X, Balan V, Tai G and Raz A: Galectin-3 induces cell migration via a calcium-sensitive MAPK/ERK1/2 pathway. Oncotarget 5: 2077-2084, 2014.

35. Hsieh YS, Chu SC, Yang SF, Chen PN, Liu YC and Lu KH: Silibinin suppresses human osteosarcoma MG-63 cell invasion by inhibiting the ERK-dependent c-Jun/AP-1 induction of MMP-2. Carcinogenesis 28: 977-987, 2007.

36. Fromigué $\mathrm{O}$, Hamidouche $\mathrm{Z}$ and Marie PJ: Statin-induced inhibition of 3-hydroxy-3-methyl glutaryl coenzyme a reductase sensitizes human osteosarcoma cells to anticancer drugs. J Pharmacol Exp Ther 325: 595-600, 2008. 